(c) 2016 European Association of Geochemistry

\section{A cometary origin for martian atmospheric methane}

M. Fries ${ }^{1 *}$, A. Christou ${ }^{2}$, D. Archer ${ }^{3}$, P. Conrad ${ }^{4}$,

W. Cooke ${ }^{5}$, J. Eigenbrode ${ }^{4}$, I.L. ten Kate ${ }^{6}$, M. Matney ${ }^{1}$ P. Niles ${ }^{1}$, M. Sykes ${ }^{7}$ A. Steele ${ }^{8}$, A. Treiman ${ }^{9}$

\section{Abstract}

Methane has been reported repeatedly in the martian atmosphere but its origin remains an obstinate mystery. Possible sources include aqueous alteration of igneous rocks, release from ancient deposits of methane/water ice clathrates, infall from exogenous sources such as background interplanetary dust, or biological activity. All of these sources are problematic, however. We hypothesise that delivery of cometary material includes meteor outbursts, commonly known as "meteor showers", may explain martian methane plumes. Correlations exist between the appearance of methane and near-approaches between Mars and cometary orbits. Additional correlations are seen between these interactions and the appearance of high-altitude dust clouds on Mars, showing that large amounts of material may be deposited on Mars during these encounters. Methane is released by UV breakdown of delivered cometary material. This hypothesis is testable in future Mars/cometary encounters. A cometary origin for me This hypouthe from any geological or biological processes on Mars.

Received 15 July 2015 | Accepted 1 November 2015 | Published 2 December 2015

\footnotetext{
NASA Johnson Space Center, Astromaterials Research and Exploration Science (ARES), Houston, TX 77059, USA

Corresponding author (marc.d.fries@nasa.gov)

2. Armagh Observatory, College Hill, Armagh BT61 9DG, Northern Ireland

Jacobs, NASA Johnson Space Center, Houston, TX 77059, USA

4. NASA Goddard Space Flight Center, Greenbelt, MD 20771, USA

5. NASA Marshall Space Flight Center, Huntsville, AL 35812, USA

6. Department of Earth Sciences, Utrecht University, Netherlands

7. Planetary Science Institute, Tucson, AZ 85719-2395, USA

8. Geophysical Laboratory, Carnegie Institution for Science, Washington DC, USA

Lunar and Planetary Institute, Houston, TX 77058, USA
}

\section{Introduction}

Investigators have reported methane in the martian atmosphere using a variety of analytical techniques, including Earth-based astronomical observations (Krasnopolsky et al., 1997, 2004; Mumma et al., 2009; Krasnopolsky, 2011), the Planetary Fourier Spectrometer on the ESA Mars Express mission (Formisano et al., 2004), and recently by the NASA's Sample Analysis at Mars (SAM) investigation on the Mars Science Laboratory (MSL) mission (Webster et al., 2015). The earliest report of methane to withstand scrutiny was made in June of 1988 (Krasnopolsky et al., 1997), and reports made since that date include several values of $\sim 10$ parts per billion by volume (ppbv) over large spatial scales (Krasnopolsky et al., 2004; Formisano et al., 2004; Krasnopolsky, 2011), several non-detections of methane (Villanueva et al., 2013; Webster et al., 2014), and "plumes" ranging up to 45 (Mumma et al., 2009; Geminale et al., 2011) to 60 ppbv (Fonti and Marzo, 2010). Local plumes of methane have been noted over Syrtis Major (Mumma et al., 2009), the north polar region (Geminale et al., 2011), Valles Marineris (Krasnopolsky et al., 1997) and other localities, but plumes have not been observed to re-occur at the same sites. Similarly, statistical studies of data from Mars-orbiting satellites also show that while methane concentrations vary regionally, those variations are not predictably consistent with latitude, longitude, or seasonal changes on the planet (Geminale et al., 2008, 2011; Webster et al., 2015).

To date, several possible sources for martian methane have been proposed, including: abiological sources such as volcanism (Wong et al., 2003), exogenous sources to include infall of interplanetary dust particles (IDP) and cometary impact material (Schuerger et al., 2012), aqueous alteration of olivine in the presence of carbonaceous material (Oze and Sharma, 2005), release from ancient deposits of methane clathrates (Chastain and Chevrier, 2007), or via biological activity (Krasnopolsky et al., 2004). Methane that was recently reported in martian meteorites (Blarney et al., 2015) may arise from serpentinisation or condensation from a carbon-bearing gas during crystallisation of its parent magma at low oxygen fugacity (Steele et al., 2012). It is not clear at present whether the meteorite-hosted methane reported in Blarney et al. (2015) is related to atmospheric methane. Since neither total methane abundance nor mineralogical context are provided by the method used, it is not currently clear whether the methane is a new discovery or a component of the reduced carbon already known to exist at $20 \pm 6 \mathrm{ppm}$ concentration in martian meteorites (Steele et al., 2012). Identifying the source(s) of martian methane has potentially far-reaching importance, particularly with biogenesis as one hypothesis. Previous investigations have examined and rejected exogenous material as a source of martian methane, specifically via IDP infall and cometary impacts (Krasnopolsky et al., 2004; Webster et al., 2015).

There is a third type of exogenous source, however, that may satisfy the observed features of martian methane, namely its sudden appearance, regional scale spatial distribution, and total methane mass observed for past martian plumes. We hypothesise that this potential exogenous source of martian methane, including the appearance of plumes, may be explained by infall of carbonaceous 
material delivered into the martian atmosphere by periodic, cometary-origin meteor outbursts (or "meteor showers"). This mechanism may also explain the recently reported appearance of high-altitude dust plumes on Mars (SánchezLavega et al., 2015).

The scope of this study includes statement of a new hypothesis for formation of martian atmospheric methane via meteor outbursts, and a re-analysis of existing methane and high-altitude dust detections on Mars as a test of the hypothesis. The meteor-outburst hypothesis is inherently testable and so a strategy is presented for doing so, using currently available techniques that have been successfully employed in the past, such as Earth-based observations of methane, detection of cometary infall by orbital assets (Jakosky et al., 2015), and methane detection by the Mars Science Laboratory rover (Webster et al., 2015).

\section{Background}

All prior hypotheses for the origin of methane in the martian atmosphere presen significant challenges (Lefevre and Forget, 2009; Zahnle et al., 2011), and thus no consensus has yet emerged on methane origin. While volcanic activity (Wong et al., 2003) could potentially release methane in episodic outbursts, multiple studies have rejected that model because the martian atmosphere lacks $\mathrm{SO}_{2}$ of volcanic origin (Wong et al., 2003; Krasnopolsky, 2011), indicating that substantial volcanic activity has not occurred recently. Conversely, both serpentinisation and biological activity can produce methane but neither is conducive to sudden production of massive methane plumes such as one reported (Mumma et al. 2009) to involve the sudden release of 19,000 tonnes $\left(19 \times 10^{5} \mathrm{~kg}\right)$ of $\mathrm{CH}_{4}$

Exogenous delivery of methane by infall of IDPs or by large impacts has also been proposed. Delivery of interplanetary dust was recently confirmed by the MAVEN mission team, who detected dust at very high altitudes in the martian atmosphere (Andersson et al., 2015). An IDP origin for Mars' methane has been considered and rejected by previous authors (Formisano et al., 2004; Krasnopolsky et al., 2004; Schuerger et al., 2012; Webster et al., 2015) because the steady flux of IDPs cannot explain episodic and transient methane plumes. Cometary impacts (Kress et al., 2004) have also been ruled out due to the lack of young impact craters of suitable size, both on the planetary scale (Krasnopolsky et al., 2004) and near the MSL rover at the time the rover detected methane (Webster et al., 2015).

Cometary debris streams (Fig. S-1) also produce infall of exogenous material into the martian atmosphere. This material arises from low-velocity emissions of large particles, forming trails spanning portions of a comet's orbit (Sykes et al., 1986; Christou and Beurle, 1999; Treiman and Treiman, 2000; Christou, 2004 2010). While generally associated with short-period comets, a debris trail has also been identified in association with the long-period Halley's comet (Jenniskens, 1995). As a consequence of planetary perturbations, trails subsequently evolve into filaments and elongated streams in a larger "tube" about the comet orbit.
When Earth, Mars and other bodies pass through such structures on an annual basis, meteor outbursts, or "meteor showers" may be observed (Christou, 2004; Fig. S-1). On Earth, these streams are well known and are actually targeted for collection of cometary material using high-altitude aircraft. Here we examine the temporal, spatial, and mass distributions of "meteor outburst" infall to Mars, and show that it is a plausible candidate as a source of atmospheric methane.

\section{Meteor Showers and Methane Detection}

As a first test of the meteor shower hypothesis, we have compared the dates of previous methane detections on Mars with Mars' currently known cometary debris stream interactions (Sykes and Walker, 1992; Treiman and Treiman, 2000; Christou, 2010). Table 1 shows the dates of methane observations along with the names and dates of correlating cometary orbital interactions. All of the methane observations are taken as single observations with the exception of Mars Express data, which are retrieved from the Planetary Fourier Spectrometer (PFS) instrument via a statistical technique over the course of two months. Figure S-2 illustrates the Ls dates of methane detections by the MSL rover versus interactions between Mars and the orbits of 5335 Damocles and 1P/Halley, indicating that methane detections occurred shortly after Mars interacted with the orbits of those bodies. Values for orbital interaction minimum distances come from Christou (2010) and Treiman and Treiman (2000). Results show that all of the methane observations occur within 16 days of the near-intersection of Mars' orbit with that of a known cometary meteor stream (Table 1). Some are especially striking, such as the exact correlation between a potentially strong, $70 \pm 50{\mathrm{ppbv} \mathrm{CH}_{4}}^{\prime}$ observation reported in (Krasnopolsky et al., 1997), which occurred on the day of an encounter between Mars and debris from the Marsden group of cometary fragments. Similarly, the strong plume noted by Mumma et al. (2009) occurred only four days after the nominal closest encounter between Mars and the orbit of comet C/2007 H2 Skiff (SI-3). That comet's orbit passes only $\sim 150,000 \mathrm{~km}$ from Mars, less than half the distance from the Earth to the Moon and similar to the very close $~ 137,000 \mathrm{~km}$ pass distance between Mars and comet C/2013 A1 Siding Spring in October of 2014 (SI-1).

Some methane detections can be correlated with the same comet. One example is Comet $1 \mathrm{P} / \mathrm{Halley}$, whose orbit had close approaches to Mars at the times of methane detections in 2004 (Formisano et al., 2004), and 2013 (Webster et al., 2015). In total, all methane detections on Mars to date could be ascribed to close encounters with only seven cometary debris streams (Table 1, Column 5).

Cometary meteor showers could also be responsible for the two highaltitude dust plumes observed over Mars (Sánchez-Lavega et al., 2015). These two optically visible dust plumes occurred at elevations $>200 \mathrm{~km}$ above the martian surface, well above martian weather or dust storm phenomena ( $<60 \mathrm{~km}$ altitude). The first dust plume, on 17 May 1997, appeared on the same day as the closest approach between Mars and the orbit of comet C/2007 H2 Skiff, whose orbit 
passes only about 19 Mars diameters from the planet (Fig. 1). It is worth noting that in 2003, the closest approach between the orbit of C/2007 H2 Skiff and Mars was only four days before the large methane plume noted by Mumma et al. (2009), consistent with infall from a massive dust stream shed from Skiff (Fig. 2) The second dust plume (Sánchez-Lavega et al., 2015) was noticed on 12 March 2012, three days after the closest approach between Mars and the orbit of comet 275P/Hermann

Table 1 Reported detections on Mars and potential correlations with cometary dust streams. \begin{tabular}{|l|l|l|c|c|c|}
\hline & Date & $\begin{array}{c}\text { Days } \\
\text { between } \\
\text { Mixing } \\
\text { cometary } \\
\text { encounter } \\
\text { and } \\
\text { detection }\end{array}$ & $\begin{array}{c}\text { Encountered } \\
\text { cometary } \\
\text { orbit }\end{array}$ & $\begin{array}{c}\text { Mars/come } \\
\text { orbit distan } \\
\left(10^{\wedge}-3 \mathrm{AU}\right)\end{array}$ \\
\hline
\end{tabular}

\section{Martian methane: Earth-based telescopic observations}

\begin{tabular}{|l|c|c|c|c|c|}
\hline Krasnopolsky et al., 1997 & 28-Jun-88 & $70+/-50$ & 0 & $\begin{array}{c}\text { (SDA Meteor Shower) } \\
\text { Marsden Group Comets }\end{array}$ & $16.139^{*}$ \\
\hline Krasnopolsky et al., 2004 & 24-Jan-99 & $10+/-3$ & 6 & C/1854 L1 Klinkerfues & $4.778^{*}$ \\
\hline \multicolumn{1}{c|}{} & 27-Jan-99 & $10+/-3$ & 9 & C/1854 L1 Klinkerfues & $4.778^{*}$ \\
\hline Mumma et al., 2009 & 11-Jan-03 & $\max . \sim 40+/-6$ & 4 & C/2007 H2 Skiff & $0.845^{*}$ \\
\hline Krasnopolsky, 2011 & 10-Feb-06 & $\sim 10$ & 15 & 13P/Olbers & $26.580^{*}$ \\
\hline
\end{tabular}

Martian methane: ESA Mars Express orbiter observations

\begin{tabular}{|c|c|c|c|c|c|}
\hline Formisano et al., 2004 & Tan-Feb 2004 & $10+/-5$ & 3 & 1P/Halley & $66.965^{*}$ \\
\hline \multicolumn{5}{|l|}{ Methane: Mars science laboratory rover } \\
\hline Webster et al., 2014 & $16-J u n-13$ & $5.78+/-2.27$ & 16 & 1 P/Halley & $66.965^{*}$ \\
\hline$"$ & 23-Jun-13 & $2.13+/-2.02$ & & & \\
\hline$"$ & $29-$ Nov-13 & $5.48+/-2.19$ & 16 & 5335 Damocles & $53.630^{*}$ \\
\hline$"$ & 6-Dec-13 & $6.88+/-2.11$ & & & \\
\hline$"$ & 6-Jan-14 & $6.91+/-1.84$ & & & \\
\hline$"$ & 28-Jan-14 & $9.34+/-2.16$ & 4 & 275 P/Hermann & $8.600^{* *}$ \\
\hline$"$ & $17-$ Mar-14 & $0.47+/-0.11$ & & & \\
\hline$"$ & 9-Jul-14 & $0.9+/-0.16$ & & & \\
\hline
\end{tabular}

Visible dust: Earth-based/Hubble telescopic observations

\begin{tabular}{|c|c|c|c|c|c|}
\hline Sanchez-Lavega et al., 2015 & 17-May-97 & & 0 & C/2007 H2 Skiff & $0.845^{*}$ \\
\hline$"$ & 12-Mar-12 & & 3 & 275P/Hermann & $8.600^{* *}$ \\
\hline \multicolumn{6}{|l|}{ Non-detections } \\
\hline \multirow[t]{4}{*}{ Villanueva et al., 2013} & 6-Jan-06 & 0 & - & - & - \\
\hline & 19-Aug-09 & 0 & - & - & - \\
\hline & 20-Nov-09 & 0 & - & - & - \\
\hline & 28-Apr-10 & 0 & - & - & - \\
\hline Mumma et al., 2009 & 26-Feb-06 & 0 & - & - & - \\
\hline \multirow[t]{3}{*}{ Webster et al., 2014} & 25-Oct-12 & $-0.51+/-2.83$ & - & - & - \\
\hline & 27-Oct-12 & $1.43+/ 12.47$ & - & - & - \\
\hline & 27-Nov-12 & $0.6+/-2.15$ & - & - & - \\
\hline$"$ & 9-Jul-14 & $0.99+/-2.08$ & & & \\
\hline Krasnopolsky, 2011 & 7-Dec-09 & 0 & - & - & - \\
\hline
\end{tabular}

* Christou, 2010

** Treiman and Treiman, 2000

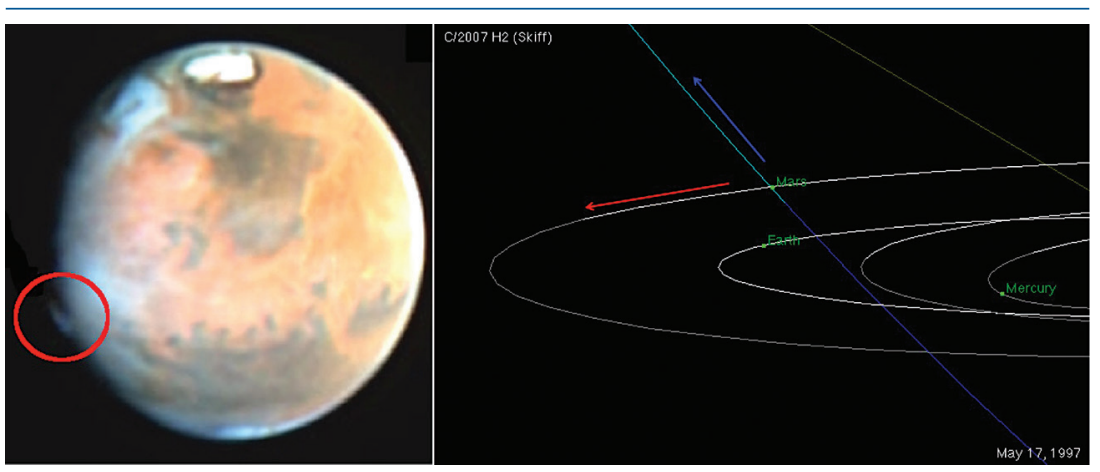

Figure 1 (left) Image adapted from Sánchez-Lavega et al. (2015) showing a high-altitude dust plume that was seen to appear suddenly on Mars. (right) The locations of Mars and the orbit of comet C/2007 H2 Skiff on 17 May 1997, the same day the dust plume appeared. The motion of Mars is shown by the red arrow and the motion of debris along the orbit of comet Skiff is shown by the blue arrow. Image: JPL Small Bodies Database. 


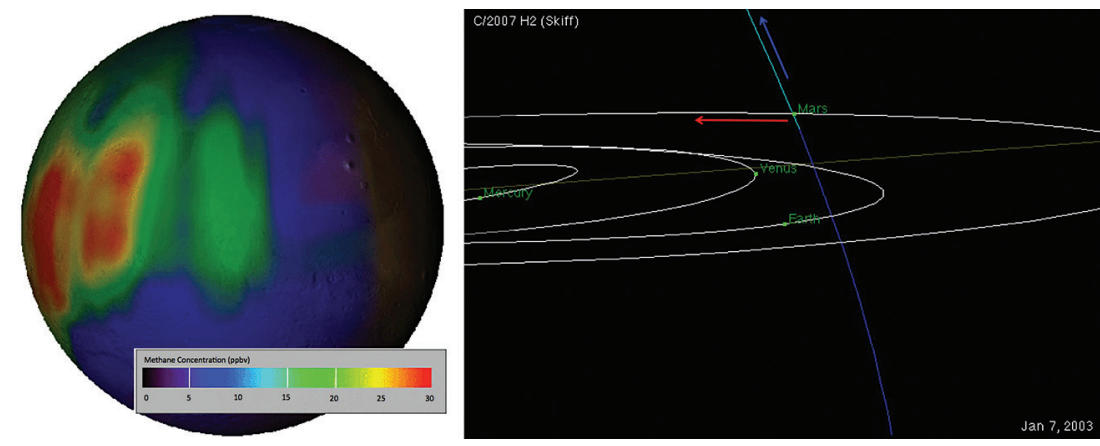

Figure 2 (left) Methane plume reported by Mumma et al. (2009) showing methane detected in the martian atmosphere on 11 Jan 2003. Image originally from NASA. (right) The locations of mately as seen from Earth. The red arrow shows Mars' direction and the blue arrow shows the movement of debris along Skiff's orbit. Image: JPL Small Bodies Database.

The areal extent of meteor showers is in agreement with the areal extent observed for martian methane plumes. Meteor showers typically peak over a course of hours, depositing material onto an area that can be sub-hemispherical in extent (Jenniskens, 1995), which is in agreement with the size of the Mumma et al. (2009) plume.

At first glance it may appear straightforward to test this hypothesis via a statistical comparison between methane detection events and the known frequency of interactions between Mars and cometary orbits. Unfortunately this approach is ambiguous because the occurrence of a Mars/comet orbit interaction does not guarantee the infall of a sizable amount of material into Mars atmosphere (e.g., Jenniskens, 2006). The distribution of cometary debris along a comet's orbit is subject to multiple stochastic processes, including the ejection of material from the parent body and dynamical perturbations of debris. Attempts to correlate orbital interactions with methane detection will result in a large number of false negative results.

\section{The Methane Source}

Having shown that methane 'plumes' on Mars are consistent in space and time with meteor shower infall, it remains to be shown that methane can be generated from that infall, and that the mass of methane generated is consistent with the observed baseline and transient abundances. Methane from meteor outbursts is not delivered directly to Mars, but is generated by UV photolysis of macromolecular carbon (MMC) solids under Mars ambient conditions (Keppler et al., 2012; Schuerger et al., 2012). The amount of methane that can be generated through a combination of IDP flux and meteor showers is generally consistent with historical methane observations on Mars. The abundance of methane in the martian atmosphere is not simply a global average, as seen in Figure S-1. Instead, periods of non-detection are punctuated by occasional observations that are usually around $10 \mathrm{ppbv}$ with episodic plumes featuring local concentrations of up to $\sim 45$ and $60 \mathrm{ppbv}$ as explained above. This is broadly consistent with a steady background IDP flux that is punctuated by periodic meteor showers that vary widely in delivered mass (Fig. S-1). Geminale et al. (2008) found that $2.7 \times 10^{5}$ $\mathrm{kg}$ of $\mathrm{CH}_{4} \mathrm{yr}^{-1}$ are necessary to sustain $10 \mathrm{ppbv}$ methane on Mars. Previous investigations have noted that IDP flux is sufficient to provide this amount (Geminale et al., 2008; Keppler et al., 2012) via UV photolysis of methane from IDPs under Mars-ambient conditions (Keppler et al., 2012; Schuerger et al., 2012). However Schuerger et al. (2012) dispute the $10 \mathrm{ppbv}$ finding and calculates that IDP flux provides a global average of $2.2 \mathrm{ppbv} \mathrm{CH}_{4}$. The MSL rover data thus far show a background methane abundance of $\sim 0.7 \mathrm{ppbv}$ (Webster et al., 2015), for which Schuerger's 2.2 ppbv is excessive if MSL's measurements are representative of the full thickness of the martian atmosphere. Overall, martian methane is at very low abundances at ground level with both non-detections and higher values noted in measurements made through the full height of the martian atmosphere. Also IDP flux may account for all or some of the steady-state background but cannot account for methane plumes.

Martian methane plumes may be attributable to periodic meteor showers. The appearance of methane plumes correlates with Mars' interactions with known cometary orbits as seen in Table 1, but meteor showers must produce enough mass to account for observed methane abundance. To produce a $1.9 \times 10^{7} \mathrm{~kg} \mathrm{CH}$ plume like that in Mumma et al. (2009) requires $7.9 \times 10^{8} \mathrm{~kg}$ of infalling material, assuming $20 \%$ UV photolysis yield (Schuerger et al., 2012) of 12 wt. \% carbon (Thomas et al., 1993; Flynn, 1996). This amount is equal to $100 x$ the annual IDP flux in a single event. Cometary debris streams can include billions of $\mathrm{kg}$ of material in total (Jenniskens, 2006) spread out into debris streams and Mars would have to interact with a local concentration to generate a meteor shower with a high local methane concentration. Mitigating factors include the fact that the $1.9 \times 10^{7} \mathrm{~kg}$ value has been challenged (Zahnle et al., 2011) as an artifact of terrestrial ${ }^{13} \mathrm{C}$-bearing methane and probably indicates an upper limit for the plume, and that the comet implicated in the $19 \times 10^{5} \mathrm{~kg}$ methane detection C/2007 H2 Skiff, may simply be capable of meteor showers of this magnitude. Material ejected from long period comets such as C/2007 H2 Skiff are known to generate episodic meteor outbursts at the Earth (Flynn and McKay, 1990), and the passage of Skiff's orbit near Mars in 1997 correlates exactly with the appearance of a dust plume that was dense enough to be visible to amateur astronomers on Earth (Sánchez-Lavega et al., 2015). Additionally, while Flynn and McKay (1990) found that about 3x more cometary material survives unmelted on Mars than on Earth, that paper disregarded material that melts during infall because that carbon does not "survive" the process. This is a valid assumption on Earth where the atmosphere contains $\sim 21 \%$ oxygen and melting a particle will combust the carbonaceous fraction. On Mars, however, the $95 \% \mathrm{CO}_{2}$ atmosphere should 
restrict combustion, driving direct devolatilisation of light species to include methane. The melted mass disregarded in Flynn (1996) amounts to $29.1 \%$ of the total IDP carbon delivered to Mars annually, constituting significant additional methane from infall sources. The portion of particles experiencing greater than $50 \%$ melting is composed of particles greater than $10^{-4} \mathrm{~g}$ in mass (Flynn, 1996), and this larger mass fraction is important because lunar impact monitoring programs indicate that meteor streams contain a higher flux of large ( $>30 \mathrm{~g})$ meteoroids than the IDP population (Oberst and Nakamura, 1991; Lyytinen and Jenniskens, 2003; Suggs et al., 2014), which is dominated by particles of $10^{-6}-10^{-4}$ g (Gruen et al., 1985). In fact, larger particles are preferentially concentrated in the vicinity of comet orbits (Asher and Izumi, 1998; Dubietis and Arlt, 2007), as observed directly in dust trails (Sykes et al., 1986). Finally, larger masses tend to generate significant amounts of micrometre-sized "smoke" particles upon infall (Klekociuk et al., 2005) that may be particularly conducive to generation of methane via UV photolysis due to their large amount of freshly-exposed surface area. These considerations collectively suggest that the total mass of carbon delivered to the martian atmosphere by meteor streams may exceed prior estimates.

Also, two of the methane plumes reported on Mars (Fonti and Marzo, 2010 Geminale et al., 2011) were recognised only through statistical treatment of orbital imagery data, and so are of uncertain spatial extent. Only the plume reported by Mumma et al. (2009) is resolved well enough in area to permit a credible estimate of its total methane mass, and even this has been challenged (Zahnle et al. 2011). It is possible that the other two plumes are strong local concentrations of a significantly lower total mass of methane.

\section{The Methane Sink}

A cometary debris origin for martian methane may also assist in explaining the observed methane loss rate, which other authors have noted to be inconsistent with currently understood martian atmospheric and surface chemistry (Krasnopolsky et al., 2004; Geminale et al., 2008; Lefevre and Forget, 2009; Zahnle et al., 2011; Webster et al., 2015). Webster et al. (2015) noted that some mechanism must be responsible for methane destruction that is "a factor of $\geq 100$ " more efficient at destroying methane than surface-level UV photolysis (Fig. S-3). However, with the exception of the MSL rover detection, all detections of methane on Mars have been obtained through the full column of the martian atmosphere and the methane has been assumed to originate from, at or near the surface. Furthermore the MSL report is a point measurement for which the areal and altitudinal extent of the methane is unknown. If, instead, methane is generated at high altitude via cometary debris origin, then the destruction kinetics of martian methane must be revisited. Wong et al. (2003) found that UV photolysis at altitudes greater than $80 \mathrm{~km}$ above Mars' surface can dominate the methane destruction rate, which may explain the observed destruction rate of methane on Mars noted by Webster et al. (2015). The correlation between observed methane depletion rates and the high-altitude methane loss rate is consistent with a cometary debris origin for Mars' methane. We also considered dust storms as a methane sink but did not find a correlation with methane non-detection (SI-2).

\section{Discussion}

If the hypothesis of a cometary meteor outburst source for martian methane is proven true, then a long-standing mystery in Mars science will be resolved. Moreover, a new mechanism will be shown that is entirely atmospheric and cometary in origin, with a source that is entirely uninvolved with either martian geology or potential biology. The hypothesis is innately testable with presently deployed assets including investigations at Mars: MSL's SAM investigation and the instrument suite on the MAVEN mission. The upcoming ESA Trace Gas Orbiter will also serve a valuable role, and of course Earth-based astronomical observations remain a valuable asset. Together, these assets should undergo an extended investigation of martian atmospheric methane that includes long-term monitoring to identify when plumes occur, how long they persist, their extent and total methane mass, and the vertical distribution of methane through the full height of the martian atmosphere. Methods used specifically to test the hypothesis of a cometary origin include observations of martian meteor showers (Adolfsson et al., 1996; McAuliffe and Christou, 2006; Domokos et al., 2007) and corresponding detection of magnesium in the martian atmosphere from meteoritic input (Jakosky et al. 2015) at the time of predicted interactions between Mars and cometary orbits, coupled with both areal and vertical distribution of atmospheric methane and high-altitude dust. Upcoming Mars/cometary interactions are listed for this purpose in Table 2. Although meteor shower-origin methane may account for observations of methane seen to date, we stress that it does not necessarily exclude the possibility of methane contributions from other sources. Our hypothesis is not only testable going forward, but presently offers a very promising set of observed correlations that may provide an explanation for previous methane detections on Mars.

Table 2 Approximate upcoming Mars / cometary orbit encounters.

\begin{tabular}{|l|c|}
\hline \multicolumn{1}{|c|}{ Comet } & Date \\
\hline 275P/Hermann & 12-Dec-15 \\
\hline C/2007 H2 Skiff & 8-Mar-16 \\
\hline (SDA Meteor Shower) & 12 -Sep-16 \\
\hline 1P/Halley & 8-Mar-17 \\
\hline 13P Olbers & 10 -May-17 \\
\hline 5335 Damocles & 16 -Aug-17 \\
\hline
\end{tabular}




\section{Acknowledgements}

The authors extend thanks to Drs. David Draper and Petrus Jenniskens, and Ms. Linda Fries for their helpful commentary and assistance. M. Fries also expresses appreciation to Dr. Betsy Pugel for all the caffeine and integrity.

Editor: Eric H. Oelkers

\section{Additional Information}

Supplementary Information accompanies this letter at www.geochemical perspectivesletters.org/article1602

Reprints and permission information is available online at http://www. geochemicalperspectivesletters.org/copyright-and-permissions

Cite this letter as: Fries, M., Christou, A., Archer, D., Conrad, P., Cooke, W., Eigenbrode, J., ten Kate, I.L., Matney, M., Niles, P., Sykes, M., Steele, A., Treiman, A. (2016) A cometary origin for martian atmospheric methane. Geochem. Persp. Let. 2, 10-23.

\section{References}

Adolfsson, L.G., Gustafson, B.Å., MURRAY, C.D. (1996) The Martian atmosphere as a meteoroid detector. Icarus 119, 144-152.

Andersson, L., Weber, T.D., Malaspina, D., Crary, F., Ergun, R.E., Delory, G.T., Fowler, C.M., Morooka, M.W., McEnulty, T., ERIKSSON, A.I., ANDrews, D.J., HORANYI M., Collette, A., Yelle, R., JaKoskY, B.M. (2015) Dust observations at orbital altitudes M., COLLETTE, A., YELLE, R., JA
surrounding Mars. Science 6, 6261.

AsHER, D.J., IZUMI, K. (1998) Meteor observations in Japan: new implications for a Taurid meteoroid swarm. Monthly Notices of the Royal Astronomical Society 297, 23-27.

Blarney, N., Parnell, J., McMahon, S., Mark, D., Tomkinson, T., Lee, M., Shivak, J. IZAWA, M., BANERIEE, N., FLEMMING, R. (2015) Evidence for methane martian meteorites. Nature Communications 6, 7399

CHASTAIN, B.K., CHEVRIER, V. (2007) Methane clathrate hydrates as a potential source for martian atmospheric methane. Planetary and Space Science 55, 1246-1256.

CHRISTOU, A.A. (2004) Predicting Martian and Venusian meteor shower activity. Earth, Moon, and Planets 95, 425-431.

Christou, A.A. (2010) Annual meteor showers at Venus and Mars: lessons from the Earth. Monthly Notices of the Royal Astronomical Society 402, 2759-2770.

Christou, A.A., Beurle, K. (1999) Meteoroid streams at Mars: possibilities and implications. Planetary and Space Science 47, 1475-1485.

Domokos, A., Bell, J.F., Brown, P., Lemmon, M.T., Suggs, R., Vaubaillon, J., Cooke, W. (2007) Measurement of the meteoroid flux at Mars. Icarus 191, 141-150
DUBIETIS, A., ARLT, R. (2007) Taurid resonant-swarm encounters from two decades of visual observations. Monthly Notices of the Royal Astronomical Society 376, 890-894

Farrell, W.M., Delory, G.T., Atreya, S.K. (2006) Martian dust storms as a possible sink of atmospheric methane. Geophysical Research Letters 33.

FLYNN, G.J. (1996) The delivery of organic matter from asteroids and comets to the early surface of Mars. Earth, Moon, and Planets 72, 469-474.

FLYNN, G.J., MCKAY, D.S. (1990) An assessment of the meteoritic contribution to the Martian soil. Journal of Geophysical Research: Solid Earth (1978-2012), 95, 14497-14509.

FonTI, S., MARZO, G.A. (2010) Mapping the methane on Mars. Astronomy \& Astrophysics 512, A51.

Formisano, V., Atreya, S., Encrenaz, T., Ignatiev, N., Giuranna, M. (2004) Detection of methane in the atmosphere of Mars. Science 306, 1758-1761

Geminale, A., Formisano, V., GiURAnNA, M. (2008) Methane in martian atmosphere: spatial, diurnal, and seasonal behavior. Planetary and Space Science 56, 1194-1203.

Geminale, A., Formisano, V., Sindoni, G. (2011) Mapping methane in martian atmosphere with PFS-MEX data. Planetary and Space Science 59, 137-148.

Gruen, E., ZooK, H.A., Fechtig, H., Giese, R.H. (1985) Collisional balance of the meteoritic complex. Icarus 62, 244-272

JAKOSKY, B., GReBowsKY, J., LUHMANN, J. (2015) Early MAVEN Results on the Mars Upper Atmosphere and Atmospheric Loss to Space. AAS/AGU Triennial Earth-Sun Summit 1, 20901

JENNISKENS, P. (1995) Meteor stream activity. 2: Meteor outbursts. Astronomy and Astrophysics 295, 206-235.

JenNiSKENS, P. (2006) Meteor showers and their parent comets. Cambridge University Press.

Kelley, M.S., Farnham, T.L., Bodewits, D., Tricarico, P., Farnocchia, D. (2014) A Study of Dust and Gas at Mars from Comet C/2013 A1 (Siding Spring). The Astrophysical Journal Letters 792, L16.

Keppler, F., Vigano, I., McLeod, A., Ott, U., FrÜchtl, M., RÖCKMAnN, T. (2012) Ultravioletradiation-induced methane emissions from meteorites and the martian atmosphere. Nature 486, 93-96.

KleKociuK, A.R., Brown, P.G., Pack, D.W., ReVelle, D.O., Edwards, W.N., Spalding, R.E., TAGLIAFERRI, E., YOO, B.B., ZAGaRI, J. (2005) Meteoritic dust from the atmospheric disintegration of a large meteoroid. Nature 436, 1132-1135.

KRASNOPOLSKY, V.A. (2011) Search for methane and upper limits to ethane and $\mathrm{SO}_{2}$ on Mars. Icarus 217, $144-152$

Krasnopolsky, V.A., BJoRaKer, G.L., Mumma, M.J., JenningS, D.E. (1997) High-resolution spectroscopy of Mars at 3.7 and $8 \mu \mathrm{m}$ : A sensitive search for $\mathrm{H}_{2} \mathrm{O}_{2}, \mathrm{H}_{2} \mathrm{CO}, \mathrm{HCl}$, and $\mathrm{CH}_{4}$, and detection of HDO. Journal of Geophysical Research 102, 6525-6534.

KRASNOPOLSKY, V.A., Maillard, J.P., OWEn, T.C. (2004) Detection of methane in the martian atmosphere: evidence for life? Icarus 172, 537-547.

KRESS, M.E., MCKAY, C.P. (2004) Formation of methane in comet impacts: implications for Earth Mars, and Titan. Icarus 168, 475-483

LeFEVRE, F., Forget, F. (2009) Observed variations of methane on Mars unexplained by known atmospheric chemistry and physics. Nature 460, 720-723

LISANO, M.E., BERNARD, D. (2014) An Almanac of Martian Dust Storms for In Sight project energy system design. In Aerospace Conference, 1-15

LYYTINEN, E., JENNISKENS, P. (2003) Meteor outbursts from long-period comet dust trails. Icarus $162,443-452$. 
McAulifFe, J.P., Christou, A.A. (2006) Simulating meteor showers in the Martian atmosphere. In Proceedings of the International Meteor Conference, Oostmalle, Belgium, 15-18 September 2005. International Meteor Organization, 155-160.

Moores, J.E., McConnochie, T.H., Ming, D.W., Archer, P.D., Schuerger, A.C. (2014) The Siding Spring cometary encounter with Mars: A natural experiment for the Martian atmosphere? Geophysical Research Letters 41, 4109-4117.

MoorheAd, A.V., WiEgerT, P.A., COOKE, W.J. (2014) “The meteoroid fluence at Mars due to comet C/2013 A1 (Siding Spring)." Icarus 231, 13-21.

Mumma, M.J., Villanueva, G.L., Novak, R.E., Hewagama, T., Bonev, B.P., DiSanti, M.A., MANDELL, A.M., SMITH, M.D. (2009) Strong release of methane on Mars in northern summer 2003. Science 323, 1041-1045.

OBERST, J., NAKAMURA, Y. (1991) A search for clustering among the meteoroid impacts detected by the Apollo lunar seismic network. Icarus 91, 315-325.

Oze, C., SHARMA, M. (2005) Have olivine, will gas: Serpentinization and the abiogenic production of methane on Mars. Geophysical Research Letters 32.

Sánchez-Lavega, A., García Muñoz, A., García-Melendo, E., Pérez-Hoyos, S., GómezForrellad, J.M., Pellier, C., Delcroix, M., López-Valverde, M. A., GonzálezGalindo, F., Jaeschke, W., Parker, D., Phillips, J., Peach, D. (2015) An extremely high-altitude plume seen at Mars' morning terminator. Nature 518, 525-528.

Schuerger, A.C., Moores, J.E., Clausen, C.A., Barlow, N.G., Britt, D.T. (2012) Methan from UV-irradiated carbonaceous chondrites under simulated Martian conditions. Journal of Geophysical Research: Planets (1991-2012), 117(E8).

Steele, A., McCubbin, F., Fries, M., Kater, L., Boctor, N., Fogel, M., Conrad, P. Glamoclija, M., Spencer, M., Morrow, A., Hammond, M., Zare, R., Vicenzi, E., Siljestrom, S., Bowden, R., Herd, C., Mysen, B., Shirey, S., Amundsen, H., Treiman, A., BulLOCK, E., JULL, A. (2012) A reduced organic carbon component in martian basalts. Science 337, 212-215.

SUGGS, R.M., MOSER, D.E., CoOKE, W.J., SUGGS, R.J. (2014) The flux of kilogram-sized meteoroids from lunar impact monitoring. Icarus 238, 23-36.

SYKES, M.V., WALKER, R.G. (1992) Cometary dust trails. I. Survey. Icarus 95, 180-210.

SYKeS, M.V., LebofSKY, L.A., Hunten, D.M., Low, F. (1986) The discovery of dust trails in the orbits of periodic comets. Science 232, 1115-1117.

Thomas, K.L., Blanford, G.E., KelleR, L.P., KLÖCK, W., McKaY, D.S. (1993) Carbon abundance and silicate mineralogy of anhydrous interplanetary dust particles. Geochimica et Cosmochimica Acta 57, 1551-1566.

Treiman, A.H., Treiman, J.S. (2000) Cometary dust streams at Mars: Preliminary predictions from meteor streams at Earth and from periodic comets. Journal of Geophysical Research: Planets (1991-2012), 105, 24571-24581.

VAubaillon, J., JennisKens, P. (2007) Dust trail evolution applied to long-period comet C/1854 L1 (Klinkerfues) and the $\varepsilon$-Eridanids. Advances in Space Research 39, 612-615.

Villanueva, G.L., Mumma, M.J., NovaK, R.E., Radeva, Y.L., Kaürl, H.U., Smette, A., ToKuNAGA, A., KhaYAT, A., ENCRENAZ, T., HARTOGH, P. (2013) A sensitive search for organics $\left(\mathrm{CH}_{4}, \mathrm{CH}_{3} \mathrm{OH}, \mathrm{H}_{2} \mathrm{CO}, \mathrm{C}_{2} \mathrm{H}_{6}, \mathrm{C}_{2} \mathrm{H}_{2}, \mathrm{C}_{2} \mathrm{H}_{4}\right)$, hydroperoxyl $\left(\mathrm{HO}_{2}\right)$, nitrogen compounds $\left(\mathrm{N}_{2} \mathrm{O}\right.$ $\mathrm{NH}_{3}, \mathrm{HCN}$ ) and chlorine species $\left(\mathrm{HCl}, \mathrm{CH}_{3} \mathrm{Cl}\right)$ on Mars using ground-based high-resolution infrared spectroscopy. Icarus 222, 11-27.

Webster, C.R., Mahaffy, P.R., AtreYA, S.K., Flesch, G.J., FarLey, K.A. (2014) Non-detection of methane in the Mars atmosphere by the Curiosity rover. NASA Technical Reports Server,
Document 20140010165 .
Webster, C.R., Mahaffy, P.R., Atreya, S.K., Flesch, G.J., Mischna, M.A., Meslin, P.-Y., Farley, K.A., Conrad, P.G., Christensen, L.E., Pavlov, A.A., Martin-Torres, J., Zorzano, M.-P., McConnochie, T.H., Owen, T., Eigenbrode, J.L., Glavin, D.P., Steele, A., Malespin, C.A., Archer JR., P.D., SutTer, B., Coll, P., Frissinet, C., MCKaY, C.P., Moores, J.E., SChWENZER, S.P., Bridges, J.C., NAVARRO-GonZALEZ, R., GelleRT, R., Lemmon, M.T., THE MSL Science TEAm (2015) Mars methane detection and variability at Gale crater. Science 347, 415-417.

Wong, A.S., AtreYA, S.K., ENCRENAZ, T. (2003) Chemical markers of possible hot spots on Mars. Journal of Geophysical Research: Planets (1991-2012), 108.

ZAHNLE, K, FreedMAN, R. S. CATLING, D. C. (2011) Is there methane on Mars? Icarus 212, 493-503. 